Quebec Cooperative Study of

Friedreich's Ataxia

\title{
Electroencephalographic Findings in Friedreich's Ataxia
}

\author{
G. REMILLARD, F. ANDERMANN, L. BLITZER, AND E. ANDERMANN
}

SUMMARY: Electroencephalographic racings of 50 patients who presented the classical features of Friedreich's ataxia were reviewed. Mild nonspecific abnormalities were found in $33 \%$ and consisted of:

a) Abnormal slow or irregular background rhythms in 15 patients (30\%).

b) Intermittent paroxysmal rhythms, considered to be projected from diencephalic or upper midbrain structures, in 4 patients (8\%).

c) Unilaterally absemt driving responses in 2 affected siblings (4\%).

There was no response to intermittent photic stimulation in $60 \%$ of the patients. This finding is not considered a definite abnormality, and its significance remains unclear.

Four patients (8\%) had epileptic seiz-

RÉSUMÉ: Les enregistrements électroencéphalographiques de 50 patients avec le tableau classique d'ataxie de Friedreich furent analysés. Des anomalies non-spécifiques furent mon'és chez $33 \%$ et incluaient:

a) Des rythmes de fond anormalement lents ou irréguliers chez 15 patients $(30 \%)$.

b) Des rythmes paroxystiques intermittents qui sont considérés comme étant projetés à partir des structures diencéphaliquess on du tronc cérébral supériear, chez 4 patients (8\%).

c) Des réponses d'accélération absentes unilatéralement chez deux membres d'ane même famille (4\%).

Il n'y eut pas de réponse à la stimulation photique intermittente chez $60 \%$ des patients. Cependant ceci n'est pas considéré comme définitivement anormal, et on n'en connait pas encore sa signification. wres, but of these only two had interictal epileptic abnormalities.

There was no correlation between the daration and severity of the disease and the presence of electroencephalographic abnormalities.

Friedreich's ataxia is mainly a spinal disorder. Involvement of supraspinal and in particular brain stem or diencephalic structures may be more extensive in those patients who show electrographic abnormalities. This would require confirmation with comparative data based on pathological observations.

lmpaired function of brain stem inhibitory mechanism may be responsible for the slightly raised incidence of seizures in pationts with Friedreich's ataxia and other cerebellar degenerations.

Quatre patients (8\%) ont ell des épisodes épileptiques, mais seulement 2 de ceux-ci montraient des anomalies épileptiques interictales. II "i'y avait aucane corrélation entre la durée et la sévérité de la maladie et la présence d'anomalies électroencéphalographiques. La maladie de Friedreich est avant tout an trouble spinal. Une atteinte supraspinale, en particulier du tronc cérébral on des structures diencéphaliques est peut-être plus étendue chez les patients montrant des anomalies électrographiques. Cependant, il nous manque la confirmation par les données anatomo-pathologiques.

Une atteinte fonctionnelle des mécanismes inhibiteurs du tronc cérébral est peut-être responsable de lincidence légèrement élevée de crises épileptiques dans l'ataxie de Friedreich et les autres dégénérescences cérébelleuses.

\section{INTRODUCTION}

In the first report on electroencephalographic findings in patients suffering from this disease, Guillain et al. in 1942 described 6 tracings with irregular background activity and absent response to intermittent photic stimulation and one showed bilaterally synchronous activity over frontal regions. In 1949, Davies described the electroencephalographic findings in 15 patients with Friedreich's ataxia associated with "psychic" disturbances. Three were epileptic and had epileptogenic discharges, three showed slight dysrhythmia, and nine were normal. Nayrac et al. (1953) mentioned electroencephalographic findings in four cases. In three, the tracings were normal, and in one there was absence of alpha rhythm. More recently, Badiu et al. (1968) reported the characteristics of 10 tracings in patients with Friedreich's ataxia with emphasis on the reaction to hyperventilation and intermittent photic stimulation following I.V. injection of small doses of Evipan, a short acting barbiturate. The tracings in all 10 patients were abnormal, with irregular background activity, reduction in the amount of alpha rhythm, and increased reactivity to intermittent photic stimulation and hyperventilation, especially after

\footnotetext{
Presented in part at the Annual Ski Meeting of the Eastern Association of Electroencephalographers. Jay Peak, Vermont, February 1975.

From the Montreal Neurological Institute, the Hôpital Ste-Justine. Montreal: the Centre Hospitalier de l'Université de Sherbrooke and the Clinical Research Institute of Montreal.

Reprint requests for the complete supplement on Friedreich's ataxia to: Dr. André Barbeau. Clinical Research Institute of Montreal, 110 Pine Avenue West, Montreal. H2W 1R7 Quebec. Canada.
} 
I.V. injections of low doses of Evipan. The illustrated examples of this activation, however, were suggestive of the response expected in normal individuals.

This study was prompted by a multidisciplinary investigation of Friedreich's ataxia. Its aim was to determine if electrographic abnormalities are indeed present in patients, obligate heterozygotes, siblings at risk and unaffected siblings who may be carriers of the disease, and to assess the significance of these findings.

\section{MATERIAL AND METHODS}

Electroencephalographic tracings recorded in 50 patients suffering from Friedreich's ataxia were studied. Thirty-five of the patients are currently being investigated within the Quebec Cooperative Study of Friedreich's ataxia and records of another fifteen patients were reviewed retrospectively. Criteria for diagnosis have been described in previous papers.

The EEG's were recorded using the International 10-20 electrode positions with 8 or 16 channel electroencephalographs in four different laboratories. Bipolar and monopolar montages were used. Hyperventilation and intermittent photic stimulation were carried out in most subjects.

The patients' ages ranged from 7 to 39 years. Correlation with time of onset and duration of disease was possible in all cases. Psychometric tests were available in 25 patients.

Irregularity of alpha rhythm was qualified as scant, abundant or continuous when it occurred in $1 / 3,2 / 3$ or the entire tracing respectively.

The response to hyperventilation was difficult to assess because of the variable extent of ataxia, weakness, or patient cooperation, and the lack of blood glucose determinations at the time of recording. Hyperventilation after administration of glucose was not performed. For these reasons, no conclusions could be drawn from the hyperventilation responses, but they did not appear to be abnormal.

Synchronous posterior slow waves in the theta or delta range sometimes occurring with shifting

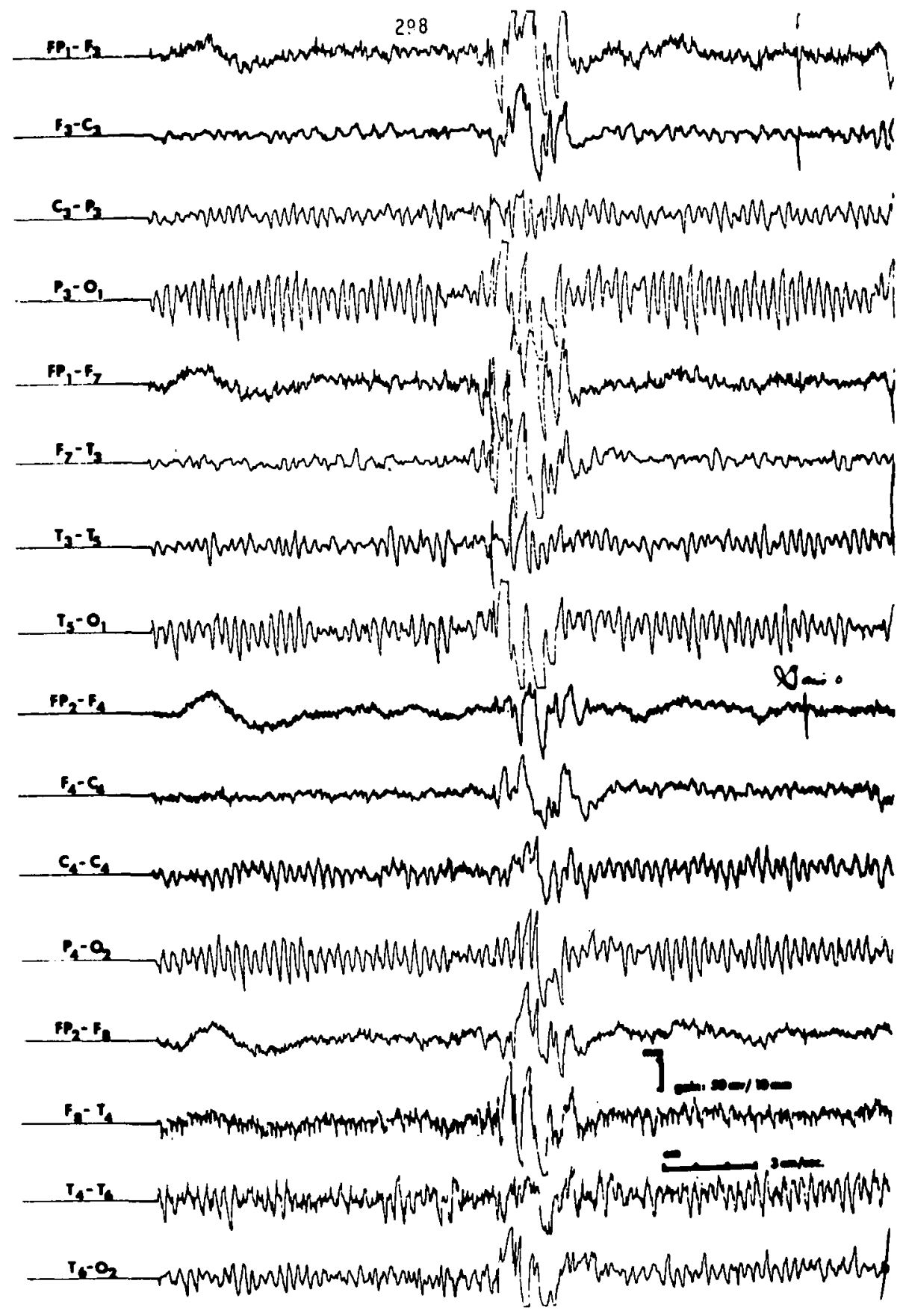

Figure I - Fourteen year old girl with Friedreich's ataxia showing high voltage 3-5 $\mathrm{c} / \mathrm{s}$ spike and wave discharges with normal background activity.

voltage predominance and fused alpha are considered normal until the age of 18 years. It did not appear that such slow activity was excessive in our patients, but this could be assessed only by comparison with an adequately age matched normal control group. Such a control series was not available to us.

Twenty-one unaffected parents and siblings were recorded. Of these, there were two siblings at risk. Twenty-four of the 50 patients were members of 9 sibships with 2 to 4 affected in each sibship. Their tracings obtained at different stages and duration of the disease could therefore be compared. Responses to intermittent photic stimulation of 44 unrelated healthy individuals ranging in age from 7 to 45 years were compared with those of the patients. 


\section{RESULTS}

Thirty-three tracings were normal. Five had scant, 9 abundant and one continuous irregularity of the alpha activity. Of these 15 patients, 5 showed intermittent low voltage theta intermingled with the background, and one, fairly continuous low voltage theta constituting most of the background activity.

Paroxysmal activity not clearly considered epileptiform occurred in two patients who had not presented any clinical evidence of seizures. In one, it consisted of short bursts of $5-6 \mathrm{c} / \mathrm{s}$ medium voltage slow sharp waves occurring at rest, replacing normal background activity. The other showed short bursts of $3 \mathrm{c} / \mathrm{s}$ high voltage slow waves, and his background activity was mildly irregular.

Four patients had a history of seizures and two of them showed interictal epileptogenic abnormalities. The first, a girl of 14, had irregular high voltage ill-defined 3-5 $\mathrm{c} / \mathrm{s}$ spike and wave discharges occurring in short bursts. Background activity was normal (Figure 1). The second, a man aged 32 , had a clinically observed tonic clonic seizure during recording. The tracing at the onset of the attack showed rapid low voltage activity followed by relatively high voltage generalized synchronous slow waves. The history was suggestive of a generalized epileptic disorder.

One patient presenting myoclonus and generalized seizures was withdrawn from the study. Although he had all other features of Friedreich's ataxia, his reflexes were hyperactive. His autopsy at age 21 showed degeneration of the brachia conjunctiva and red nuclei in addition to the classical changes of Friedreich's ataxia. Another epileptic patient presented clinical features of Friedreich's ataxia, but retained normal plantar flexor responses at age 35; he was also excluded. These two patients were not considered to have classical Friedreich's ataxia.

Intermittent photic stimulation produced no driving in 27 of 47 patients as compared to 3 of 44 normal controls, and this difference is highly

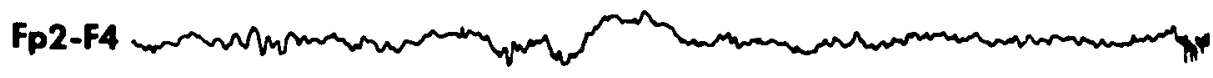

F4-C4

C4-P4

P4-02

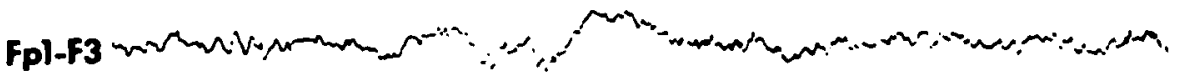
F3-63 - JU

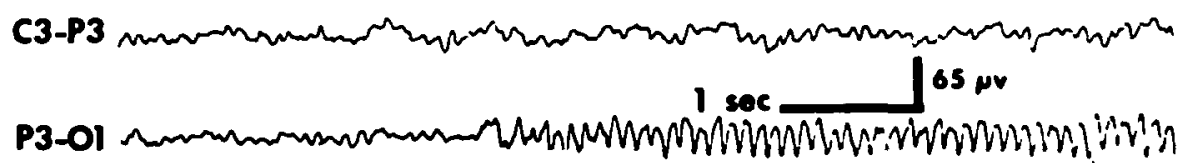

Figure 2-One of two atypical ataxia siblings with absent driving responses to photic stimulation on the right side.

significant $\left(\mathrm{X}^{2}=24.1 ; \mathrm{P}<0.001\right)$. Two affected siblings had absent driving responses to photic stimulation on the right side (Figure 2), whereas the response over the left side was active at several frequencies. Duration of illness was 4 years in one and one year in the other. The asymmetry was not present on repeated recording in one patient several years later. The handedness and visual dominance of these patients is not known and the tracing of a third affected sibling showed no asymmetry.

The 21 unaffected siblings and parents ranged in age from 8 to 82 years. Irregularity of background rhythm was scanty or abundant in 6. No abnormal theta rhythms, paroxysmal projected abnormalities, or clear-cut asymmetries of the response to intermittent photic stimulation were observed. One unaffected sibling was epileptic, but his tracing on medication was normal.

Tracings of 24 affected members of 9 sibships were available for comparative studies. In one of the families, 3 of 4 affected siblings had abundant irregularity of the background activity and in addition 2 had intermittent diffuse theta intermingled. Striking asymmetry of the driving response occurred in 2 of 3 sib- lings of another family. In a third sibship of three, 2 showed paroxysmal abnormalities, manifested by 3-5 c/s high voltage ill-defined spike and wave discharges in one and bursts of slow sharp 5-6 c/s waves in the other, while the third was normal. In a fourth family, 2 out of 3 affected siblings were epileptic, but their interictal tracings remained normal. Intermittent photic stimulation produced normal driving responses in some and no response in other affected siblings in several families.

There was no evidence for progressive decrease or increase in alpha frequency with age of affected siblings, nor was there any tendency for increasing abnormalities with the duration of illness, when affected siblings were compared.

\section{DISCUSSION}

The electroencephalographic tracings were normal in two-thirds of patients with Friedreich's ataxia in our series. This is in keeping with the fact that the pathological process in this disease produces the most striking changes at the spinal level. A variable degree of involvement of the cerebellum, brain stem, reticular formation, subthalamic nuclei and other structures is often evident his- 
tologically. This may explain some of the abnormalities observed in one third of our patients. Abnormal tracings may be considered as evidence of higher extension of the pathological process.

Some authors (Kissel et al., 1955) have suggested that electroencephalographic tracings should be part of the genetic study of siblings and parents in an attempt to find unaffected carriers and to recognize those siblings who will eventually develop the disease. Our study tends to confirm that very similar abnormalities may be present in affected members of the same family, such as the occurrence of clinical seizures, projected paroxysmal activity, irregular background activity with or without intermingled theta rhythm, and asymmetrical or absent driving responses. However, in view of the low frequency of abnormal records in affected individuals, reliance on the presence or absence of electrographic abnormalities does not appear to be helpful in establishing a preclinical diagnosis, or in the detection of asymptomatic carriers. Some of the 21 tracings obtained in parents and siblings showed irregularities of background activity, but the frequency and degree were not greater than expected in the normal population.

A striking abnormality with synchronous delta activity over posterior head regions was seen in affected members of one family not included in this study. It represented a genuine projected abnormality originating in deep midline struc- tures. We were surprised not to find this type of discharge in the present series, where the occipital slow activity appeared physiological, and compatible with the patients' ages.

Intermittent photic stimulation produced a driving response significantly less often in patients with Friedreich's ataxia than in their normal relatives and in a normal control group. The reason for this is unclear.

That seizures with or without myoclonus may occur in patients considered to have Friedreich's ataxia has been known since Ramsay Hunt's classical article appeared in 1921. He described twins with myoclonus and seizures who later developed an ataxic disorder with areflexia, but who retained flexor plantar responses. We have excluded from our study such a patient since he did not appear to have typical signs of Friedreich's. Another patient excluded from our study corresponded surprisingly well to the cases described by Crighel and Jonasescu (1962) who had many of the signs of Friedreich's ataxia. Epilepsy and generalized spike and wave discharges have also been described (Louis-Bar and Van Bogaert, 1947; Vallat, 1957).

The lesions of Friedreich's ataxia may, through removal of inhibition on cortical structures, explain the slightly increased frequency of epilepsy we have found in patients with this disorder $(8 \%)$, and the association of epilepsy with other spinocerebellar degenerations.

\section{ACKNOWLEDGMENTS}

The studies reported in this paper were partially supported by L'Association Canadienne de l'Ataxie de Friedreich and the Medical Research Council of Canada.

\section{REFERENCES}

BADIU, G., and POPESCU-TISMANA, G. (1968). Some electroencephalographic features of spino-cerebellar degeneration. Confin. Neurol., 30, 261-271.

CRIGHEL, E., and JONASESCU, H. (1962). Electroencephalographic findings in 2 families with Friedreich's ataxia. Confin. Neurol., 22, 28-39.

DAVIES, D. (1949). Psychiatric changes associated with Friedreich's ataxia. J. Neurol. Neurosurg. Psych., 12, 246-250.

GUILLAIN, G., BERTRAND, I., GODET, J., and GRUNER, J. (1942). L'électroencéphalogramme dans la maladie de Friedreich. C. R. Soc. Biol., 136, 494-495.

HUNT, R. (1921). Dyssynergia cerebellaris myoclonica - primary atrophy of the dentate system: A contribution to the pathology and symptomatology of the cerebellum. Brain, 44, 490-538.

KISSEL. N. P.. ARNOULD, G.. HARTMAN, P.. DUREUX. J. and DEBRY. G. (1955). L'électroencéphalogramme dans la maladie de Friedreich. Rev. Neurol., 93, $761-764$.

LOUIS-BAR, D., and VAN BOGAERT, L. (1947). Sur la dyssynergie cérébelleuse myoclonique (Hunt). Wschr. Psychiat. Neurol., 113, 215-247.

NAYRAC, P., WAROT, P. and WILLEMS, G. (1953). Maladie de Friedreich atypique ou maladie de Roussy-Levy. Echo. Med. Nord., 24, 275-279.

VALLAT, J. N. (1957). Etude clinique et électroencéphalographique d'un cas de dyssynergie cérébelleuse myoclonique associée à une maladie de Friedreich. Rev. Neurol., 96, 75-81. 